\title{
Anti-crisis Management Strategy for a Construction Organization during an Economic Downturn Amid a Pandemic and Lockdown
}

\author{
Maria Romanenko* \\ Penza State University of Architecture and Construction, 28 German Titov, Penza, 440028, Russia
}

\begin{abstract}
Anti-crisis management of a construction organization during the period of general economic development is the main part of its strategic development. It is necessary to ensure the stable functioning and monitoring of the state of the enterprise in the construction market. The existing management models are not fully adapted to the current situation during a pandemic, lockdown and crisis phenomena. Development of updated schemes and models, including a tactical action plan in the short term, ensuring the survival and development of the organization in conditions of uncertainty. The introduction of the proposed measures for anti-crisis management based on the predicted results of the activities of enterprises and the development of the economic situation in specific conditions makes it possible to minimize losses and ensure a further smooth way out of the current crisis crisis.
\end{abstract}

Strategic planning consists in developing probable plans for the development of the situation, which allow you to choose one solution that is acceptable for a given construction company. Such a strategic approach allows in a short time to organize fast copying of competitors' products, borrowing of technological processes, which can significantly increase labor productivity and reduce the cost of production. This contributes to successful functioning among competitors, but does not provide protection against accidents and unpredictable phenomena of crisis situations [1].

With the onset of a crisis, construction organizations are faced with unforeseen costs, a slowdown in the turnover of financial resources, goods and a drop in demand for the services themselves. Consequently, the management system of any organization should be based on continuous improvement of the strategic management system and its relationship with the methods of anti-crisis adjustment. Simultaneous improvement of strategic management processes and methods of anti-crisis stimulation of production significantly reduces the vulnerability of the organization $[1,2]$.

A crisis can be viewed as an event that goes beyond the usual course of economic and political events, which leads to instability of the organization, reorientation of goals, disruption of strategic management in management, the company faces unpredictable and sudden catastrophic consequences. changes that cannot be controlled $[3,4]$.

* Corresponding author: romanenko.masha@yandex.ru 
Crisis phenomena can be divided into three groups. The first group is an organized economic crisis; the second group - natural disasters, epidemics, pandemics; the third is the combination of the first two. Let's consider all the groups one by one.

The organizational crisis is based on the collapse of economic ties due to overproduction, ignoring the laws of economic development of commodity production, leading to massive bankruptcy, job cuts, and a decrease in the need for services. Against this background, strikes develop, which leads to political instability. Logistic connections between producers and consumers are violated [5].

Uncertainty of cause-and-effect relationships does not allow predicting the onset of a critical situation for an organization and timely taking effective methods aimed at getting out of this situation $[5,6]$.

The crisis, absorbing all spheres of the economy, generates cognitive phenomena that contradict rational actions, which cannot be eliminated using only traditional methods of enterprise management. The following problems arise:

- problematic choice of decision making from a large number of possible ones;

- reduction of opportunities for construction organizations during the crisis;

- a small fraction of the likelihood that the organization will cope with the consequences of the crisis;

- ambiguity and uncertainty of cause-and-effect relationships.

The second group, which includes natural disasters, epidemics, pandemics, is capable of leading the economy of not only one sector of the country to crisis phenomena, but of the entire world community as a whole. An example is the situation in the world in 2019-2021, when the COVID-19 pandemic led to the closure of a number of countries in Europe, America, Asia to quarantine, to lockdown, which led to the disruption of communication links between countries, the movement of labor resources, and a shortage of medicines and equipment. But the economy suffers the most due to the closure of businesses, transport, an increase in the number of unemployed around the world and victims from COVID-19. Countries are forced to channel their financial resources to combat the pandemic in medicine and pharmacology to develop a vaccine. There is an increase in the pretentious movement of the population.

The third group of crisis phenomena is developing against the background of the joint manifestation of an organizational and natural-pandemic crisis. This phenomenon is characterized not only by economic, political, but also social, environmental consequences, which are severely reflected in the psychological state of human society. People experience fear, depression, and there is a lack of faith in the future among the population. Corruption and theft are flourishing in all spheres of human activity, but at the same time the volunteer movement is growing [7-9].

Let's consider the differences between strategic management and anti-crisis management. In strategic management, there are three main components, namely: the strategy of forming a decision; implementation of the chosen strategy; an objective assessment of the decision made. With such strategic management, the general general goal of management is established, the intermediate results of the organization are considered in planning. However, there is no possibility of predicting threats from both external and internal factor space. The consequences of the impact of technical progress on the environment, social life of society and the psychological state of people are not taken into account - the ultimate goal is set at the head, for the achievement of which a strategy is formed that does not take into account the consequences of the enterprise's activities [1,9].

The process of implementing the chosen strategy is based on fixing the results achieved at certain time stages, for example, a week, a month, a quarter, half a year, a year. Of great importance during this period is the revision of the organization's financial policy, the choice of funding sources, the optimization of the staffing table, a change in the policy of bonus 
payments to top managers, if necessary, an emergency rotation or complete change of the management of companies and organizations $[5,10,11]$

Evaluation of the strategy includes obtaining feedback on the decisions made and analyzing the current work of the organization on the adopted plan for the implementation of the strategic plan. Moreover, the process of strategic control in the tactical management scheme is considered to control and adjust the decisions made due to the unpredictability and sudden changes in events in the service market and at the legislative level [12]. The information obtained requires the development of a theory to anticipate the consequences of the decisions made.

Anti-crisis management is aimed at identifying weak decision-making methods and anticipating all kinds of malfunctions due to the general economic crisis. This takes into account the constructive and destructive factors, the state and development of both technologies and technology. A number of questions arise: how do people themselves react to all kinds of risks associated with the crisis; how exactly this can be taken into account in anti-crisis management; How does an organization create a sustainable competitive advantage in the industry for itself? There is no unambiguous answer to the above questions. It is worth paying attention to the fact that the management of a company or organization is aimed at protecting the interests of shareholders of enterprises (beneficiaries), employees, investors, government agencies. However, it is impossible to satisfy the interests of everyone in a crisis situation; it is necessary to make a choice $[13,14]$.

To achieve the success of an organization in a crisis situation, it is necessary to have successful management in a period of high uncertainty in decision-making. Organizations must accurately follow the planned roadmap to obtain information about the opportunities and threats of factor space and the environment, so that a strategy for using existing resources and methods of protection against negative influences can be systematized in time. At all stages of management, at least small, but success should be shown on the basis of foreseeing the development of events. In this, we can consider the synergistic effect of the integration of strategic management with anti-crisis management $[15,16]$.

In a pandemic that has affected all countries of the world, organizations seeking to maintain stability of functioning need to rely on modeling methods, outsourcing, reengineering, integrated quality management, restructuring of financial obligations, optimization of the staffing table, which will provide a competitive advantage over others.

The forecasting methods used by management are based on SWOT analysis, portfolio analysis and Q-Sort analysis. In particular, the SWOT analysis allows you to take into account both the weak and the strengths of the managerial nature of the organization (internal), external threats (economic and political). Based on the results of the SWOT analysis, a general characteristic of the enterprise is created using a systematic analysis [13]. These methods are closely based on information systems and human intelligence.

Thus, anti-crisis and strategic management, complementing each other during a pandemic and global lockdown, show synergy, which makes it possible to successfully cope with the challenge of unpredictable circumstances. To do this, the construction organization needs to go through a number of stages, which are determined by the specifics of the organization's activities and the services provided.

The first stage is to create an adequate management team working both remotely - online and in the office - offline. The organization provides workers with all the hardware to operate effectively, while employees aged 65+ are provided with paid leave. Rotation of a part of top management is carried out in accordance with skills and competencies. A complete replacement of the management team is also possible as a result of actions leading to financial losses or a decrease in the competitiveness of the construction organization. Teamwork is required of both line personnel, information and analytical personnel, and management. This will ensure the vitality and performance of the organization in a crisis situation, while 
increasing labor productivity. The resource base, along with the logistics supply of materials in the context of the development of the crisis and after the crisis period, will be optimized for the strategic and tactical plans of the organization.

The second stage is considered from the point of view of efficiency and quick decisionmaking. This is ensured by a quick response to changing external and internal factors, the creation of constant monitoring of the situation, the processing of information and the issuance of forecast situations due to information support to all structural divisions and top management. Decision making is reduced from 1 to 2 hours instead of 10-20 days. Delay can lead to loss of management of the organization, disruption of the operational plan, decrease in competitive advantages in the construction market, in the worst case - absorption by a larger enterprise.

The third stage is related to the control over the implementation of the adopted decisions and the correction of operational and tactical plans. It is required to constantly coordinate the level and scale of threats to the organization of the construction industry due to the presence of dependence on the demand for construction services, the possibility of supplying construction materials and the efficiency of financial organizations in a crisis and pandemic. The crisis and its consequences are repetitive and compressed in time. The duration of the crisis and its consequences can be considered from one to ten years. Anti-crisis management should take into account the basic principles of strategic management and rely on an objective assessment of the signs characteristic of the crisis, analyze the state of the environment and social environment, and this requires financial and human sources.

The loss of control over the management of a construction organization as a result of untimely identification of the source of the developing crisis in the political, economic, social, technological, environmental and mental environment contributes to a decrease in the company's share in the construction market and the loss of a significant part of profits. Management in such a situation considers only the short-term interests of the organization and does not have a sufficient scientific and theoretical basis for building an anti-crisis program of action based on taking into account uncertainties.

The fourth stage is the formation and training of the crisis management group of the construction organization. The purpose of crisis management is to predict threats and eliminate unwanted consequences, develop contingency plans aimed at maintaining competitive advantages and working potential. For this, data obtained as a result of experimental and practical activities are used, taking into account changes in the construction industry, the legislative framework, the economic downturn, strikes by the organization's employees, an increase in interest rates, technological progress based on artificial intelligence, and a shortage of raw materials.

Mathematical processing of operational information allows you to identify nodal (sensitive) points that are corporate or functional level in the short-term or long-term strategic plan. Sensitive points of certain deviations are always associated with baseline forecasts of the state of the industry and organization. They are used to inform the management of a construction organization about the need to rethink and re-evaluate the changes made to the development strategy and provide the necessary time for making a decision $[9,13]$.

When making fundamental decisions aimed at changing strategic management in a rapidly changing environment, it is advisable to use flexible planning methods, as a rule, leading to a serious internal reform of the organization. The results of successful practical activities of the industry's locomotive enterprises serve as the basis for theoretical forecasting of the results of the implementation of anti-crisis management methods. On the basis of the analysis, a scheme for managing a construction organization during a crisis and a pandemic was proposed (Fig. 1). 


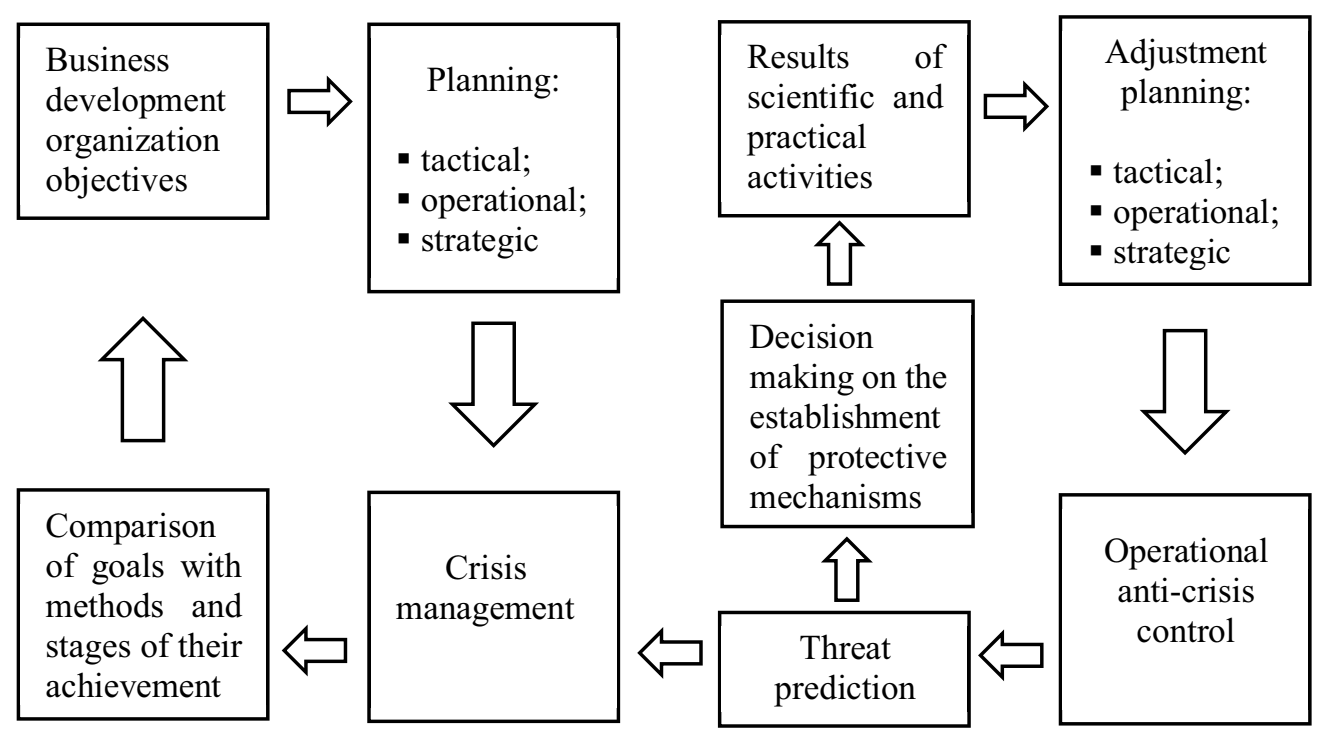

Fig. 1. Scheme of management of a construction organization during a crisis and pandemic.

In most cases, a construction organization in the context of a rapidly changing situation in the service market can partially reorient its business to the concomitant functioning of the organization in the direction of construction and move to new cooperation, far from construction, to achieve new goals, taking into account adjustments to the strategic plan. Thus, global goals during the development of the crisis should be adapted to the search and cooperation with new partners and beneficiaries, regardless of their belonging to the external or internal business environment.

The basis of anti-crisis management is the integrated research model [13]. It allows for a comprehensive assessment of critical conditions, the development of a practical plan, and the creation of strategic directions for overcoming the current situation. This is based on the sum of accumulated knowledge and experience of past generations of management.

The five-stage model is widely used to manage construction companies in Europe. The model is presented in the form of a closed loop, which includes: detection, preparedness, suppression, recovery and training.

It is worth noting the model of anti-crisis management during an economic crisis, represented by a two-stage form, which includes all missionary levels and supporting methods of phased suppression of the impact of risks on management. In the modern conditions of the XXI century, this management model is ineffective.

The anti-crisis management model defines five important stages: perspective, prevention, rescue, naturalization of production and rehabilitation of the management system of an organization affected by the crisis $[5,7]$. The main direction of the model is forecasting.

Based on the analysis of existing models, we proposed a model of anti-crisis management during a pandemic that swept the whole world, and is presented in Fig. 2. 


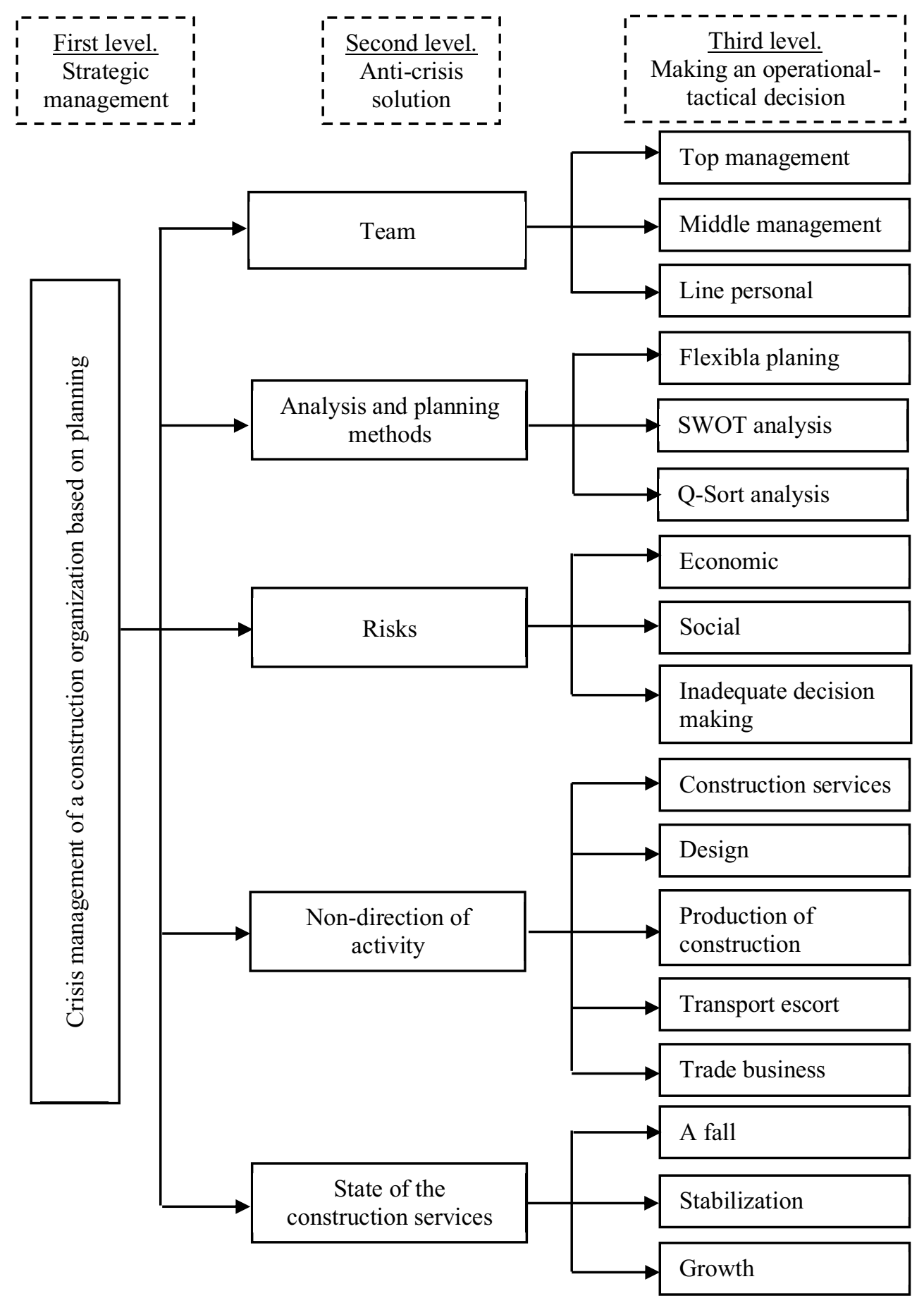

Fig. 2. Model of anti-crisis management of a construction organization during a pandemic.

The proposed model includes: creation of a new organizational structure; team building; training in anti-crisis management methods; modeling and forecasting the development of the system in conditions of uncertainty; decision making in a limited time interval; control 
over the implementation of the decisions taken. This crisis management model is based on the probabilistic occurrence of events.

\section{Conclusions}

1. The research is aimed at identifying methods by which construction organizations can cope with crises and restore their previous competitive position in the short term using flexible planning methods under conditions of uncertainty.

2. Organizations must timely form an anti-crisis management and make adjustments to operational and tactical plans.

3. Management management is formed from specialists with practical skills and competencies to work in crisis management.

4. Successful overcoming of the crisis and its consequences is possible through teamwork and as a result of timely response to constantly changing situations.

5. It is required to correctly distribute the management functions of the enterprise, taking into account the work both offline and online. The role of computerization of all management processes is growing: obtaining information, analysis, forecasting, decision-making, control over the implementation of decisions made.

6. Construction companies with different forms of ownership must constantly monitor the state and direction of development of the internal and external environment, assess the occurrence of risks.

\section{References}

1. B. Nabizade, H. Mohammad, The role of strategic management in crisis management, Crisis Management Journal, v. 15, pp. 7-40 (2012)

2. R. Hamidreza, Intermixture of Crisis Management in Guidelines of organization, Tadbir Journal, v. 177, p. 23 (2007)

3. M. Lucero, A. Kwang, A. Pang, Crisisleadership: when should the CEO step up? Corporate Communication: An International Journal, v. 26, pp. 234-248 (2009)

4. P. Altok, Applicable vision, mission and the effects of strategic management on crisis resolve, Procedia Social and Behavioral Sciences, 7th International Strategic Management Conference, pp. 61-71 (2011)

5. B. Ronald, Strategy consultants, Strategy in times of crisis, The global magazine for decision-makers, v.13, pp. 1-64 (2009)

6. R. Pearce, K. Shurini, Both simon; strategy competitive and change in modern enterprise, Planning and Strategic Management, v. 10, p. 86 (2013)

7. M. Dandira, Strategy in crisis: Knowledge vacuum in practitioners; Business strategy series, Emerald Group Publishing Limited, v. 13 (3), pp. 128-135 (2012)

8. R. Taher, A. Asghar; A. Qolipur, Codification of the comprehensive pattern for critical management with security attitude, Danesh Entezami Journal, v. 2, pp 67-72 (2009)

9. J. Panrise, The role of perception in crisis planning, Journal of Public Relations Review, v. 26, p. 2, (2000)

10. A. Pinar, Applicable vision, mission and the effects of strategic management on crisis resolve, Procedia Social and Behavioral Sciences, 7th International Strategic Management Conference, pp. 61-71 (2011)

11. A. Babaiee, Management of organizational Crises, Kamal Journal, v. 4, pp. 111-130 (2004) 
12. V. Santos, T. Garcia, The complexity of the organizational renewal decision: the management role, Leadership \& Organization Development Journal, v. 12, pp. 336-355 (2007)

13. B. Hrustalev, M. Romanenko, M. Vasyun'kova, Osnovnye varianty upravleniya innovacionno-investicionnoj privlekatel'nost'yu predpriyatij stroitel'nogo kompleksa, Ekonomika stroitel'stva, v. 3 (51), pp. 43-51 (2018)

14. O. Maslak, P. Sokurenko, B. Ievgen, Anti-crisis approach in the industrial enterprise management: methodological tools of preventive regulation, SHS Web of Conferences 73, v. 010, p. 13 (2020)

15. R. Bacik, J. Kloudova, J. Gonos, V. Ivankova, Management of Competitiveness and Economic Performance Based in the V4 Countries, Marketing and Management of Innovations, v. 3, pp. 73-88 (2019)

16. I.I. Romanenko, M.I. Romanenko, I.N. Petrovnina, Modification of the cement stone active silm of urban treatment facilities, IOP Conference Series: Materials Science and Engineering. International Conference on Modern Trends in Manufacturing Technologies and Equipment 2019, ICMTME 2019, p. 022096 (2020) 